\title{
IAP Guideline on Practicing Safely During COVID-19 Era: Clinics and Small Establishments
}

\author{
GV Basavaraja, ${ }^{1}$ Supraja Chandrasekar, ${ }^{2}$ Arun Bansal,${ }^{3}$ Dhiren Gupta,,${ }^{4}$ Bakul Jayant Parekh,,${ }^{5}$ SS Kamath, ${ }^{6}$ \\ Snehal Desai, ${ }^{7}$ Pritesh Nagar, ${ }^{8}$ Nitin Shah, ${ }^{9}$ Atanu Bhadra ${ }^{10}$ And AJ ChitKara ${ }^{11}$ For Indian ACademy Of \\ Pediatrics \\ From ${ }^{1}$ Paediatric Intensive Care Unit, Indira Gandhi Institute of Child Health, Bangluru, Karnataka; ${ }^{2}$ Columbia Asia Referral \\ Hospital, Yeshwanthpur, Bengaluru; ${ }^{3}$ Division of Pediatric Critical Care, Department of Paediatrics, Advanced Paediatrics Centre, \\ Postgraduate Institute of Medical Education and Research (PGIMER), Chandigarh; ${ }^{4}$ Pediatric Intensive Care Unit, Sir Ganga \\ Ram Hospital, New Delhi; ${ }^{5}$ President (2020), Indian Academy of Pediatrics; ${ }^{6}$ Department of Pediatrics, Indira Gandhi Cooperative \\ Hospital, Ernakulum, Kerala $;^{7}$ Amruta Hospital, Surat, Gujarat; ${ }^{8}$ Consultant Pediatric Intensivist, Hyderabad, Telangana; \\ ${ }^{9}$ Department of Pediatrics, PD Hinduja Hospital, Mumbai, Maharashtra; ${ }^{10}$ ESI Hospital, Asansol, West Bengal; and ${ }^{11}$ Department \\ of Pediatrics, Max Superspeciality Hospital, Shalimar Bagh, New Delhi; India. \\ Correspondence to: Dr Arun Bansal, Professor, Department of Pediatrics, Advanced Pediatrics Centre, Postgraduate Institute of \\ Medical Education and Research (PGIMER), Chandigarh, India.drarunbansal@gmail.com
}

Justification: The unprecedented COVID-19 pandemic has had a formidable impact on Indian health care. With no sight of its end as yet, various establishments including the smaller clinics and nursing homes are restarting full operations. Hence, there is the need for recommendations to allow safe practice ensuring the safety of both the heath care worker (HCW) and patients. Process: Indian Academy of Pediatrics organized an online meeting of subject experts on 27 July, 2020. A committee was formed comprising of pediatricians, pediatric and neonatal intensivists, and hospital administrators. The committee held deliberations (online and via emails) and a final consensus was reached by November, 2020. Objectives: To develop recommendations to provide a safe and practical healthcare facility at clinics and small establishments during COVID times. Recommendations: The key recommendation to practise safely in this setting are enumerated. Firstly, organizing the out-patient department (OPD). Secondly, appropriate personal protective equipment (PPE) to provide protection to the individual. Thirdly, decontamination/disinfection of various common surfaces and equipment to prevent transmission of infection from fomites. Next, maintaining the heating ventilation and air conditioning (HVAC) to provide a stress-free, comfortable, and safe environment for patients and HCWs. Finally, steps to effectively manage COVID-19 exposures in a non-COVID-19 facility. All these measures will ensure safe practice during these unprecedent times in clinics and smaller establishments.

Keywords: Preparedness, Physical distancing, Resource-limited setting, SARI.

$\mathrm{T}$ he healthcare industry not only bears the brunt of the coronavirus disease (COVID-19) epidemic, but has also to mitigate its spread too. In this regard, putting strict practices and processes in place that are suitable to the local needs and resources will be paramount in fighting this disease effectively.

The Indian Academy of Paediatrics (IAP) has therefore come out with the following guidelines on practicing safely in clinics and small establishments during these unprecedented times.

\section{OBJECTIVES}

To develop recommendations to provide a safe and practical health care facility at clinics and small establishments during COVID times, and to ensure safety of the healthcare workers (HCW), and patients at clinics and small establishments.

\section{PROCESS}

The Indian Academy of Pediatrics organized an online meeting of subject experts on 27 July, 2020. A committee was formed comprising of pediatricians, pediatric and neonatal intensivists, and hospital administrators. The committee held various deliberations (online and via emails) and a final consensus was reached by November, 2020.

\section{RECOMMENDATIONS}

The guidelines are applicable for clinics, polyclinics, and level 1 hospitals.

A clinic is defined as a clinical establishment providing examination, consultation, and prescription to outpatients, including dispensing medicines by a single doctor, general practitioner, specialist, or a super-specialist doctor. A polyclinic is similar but managed by more than one doctor, 
general practitioner, specialist, or a super-specialist doctor. [2] A Level 1 (A) hospital is a general medical service with an indoor admission facility, provided by recognized allopathic medical graduate(s) and may also include general dentistry services offered by recognized BDS graduates. Example: Primary Health Care Centre (PHC), government and private hospitals, and nursing homes run by MBBS doctors. A Level 1 (B) hospital shall include all the general medical services provided at level 1(A) and indoor and OPD specialist medical services provided by doctors from one or more basic specialties, namely general medicine, general surgery, pediatrics, obstetrics and gynecology, and dentistry. [3]

The guideline will be discussed under these broad subheadings

- Organising the Out Patient Department [OPD]

- Personal Protective Equipment (PPE) and Innovation

- Sanitisation Recommendations

- Heating Ventilation and Air Conditioning [HVAC]

- Protocol for post-Covid-19 exposure in a Non-Covid19 zone

\section{Organizing The Outpatient Department}

1. Staff Skills Training and Education - The first step in organizing the OPD is the education of HCW on PPE, disease transmission, screening techniques, cohorting patients, and newer clinic management protocols. [4] The clinician should be prepared for HCW's illness \& subsequent quarantine by training the staff to multitask and alternating their duties. [5] In the Indian scenario, with constraints in the availability of skilled staff, prevention is the key.

2. Tele Consultation - With the legalization of teleconsultations, it is recommended wherever feasible. [6] It helps to identify patients who can be managed at home and those who need hospital care. It minimizes patient contact and is a useful triaging tool. The teleconsultation guidelines laid down by the government need to be followed [7].

3. Appointments and Patient Scheduling - Limit the number of patients per day. Walk-In consultations should be discouraged to avoid overcrowding. Patient segregation \& triaging to be done while scheduling appointments [6].

4. Physical Distancing and Waiting Areas - Clinics should preferably have no waiting areas. However, when more than one person arrives, their seats should be at least 1 meter apart. [5,6] Open ventilation is encouraged here [refer section on HVAC]. In single room OPD

INDIAN PEDIATRICS chambers, it would be prudent to call one patient at a time; others can wait outside in the open air or their vehicles.

5. Patient Segregation - It is prudent to cohort children who are ill from the well-baby visits. Many clinics are operated only by the practicing doctor. However, it is recommended to have a helper who will assist in triaging, maintaining decorum, and educating patients. Preferably an initial screening should be followed by separation of those suspected of COVID-19 from others. These cases should not spend time in the waiting area and should be seen immediately. A separate entry, consultation place \& exit, if feasible, will help. [4] As not all clinics have the facilities mentioned above, alternate precautions should be followed:

- Telephonic triaging and schedule appointments for all suspect cases after routine OPD [6]

- Exclusive days should be allotted for 'Well baby' \& Immunization checks once or twice a week. This may even boost parents' morale who otherwise would be scared to come to clinics for vaccinations.

6. Patient Education and Awareness - All patients should follow respiratory hygiene and cough etiquette. Patients should be provided with tissues, contactless bins, contactless sanitizers, and wash areas. Display these instructions in prominent locations. Patient education is also the physician's responsibility, hence putting educative posters, multimedia information at strategic points is useful. $[4,6]$

7. One Attendant and Personal Protection - Allow only one parent or guardian with the child. [5] Everybody, including children above two years, should wear a mask.

8. Well Ventilated - Follow the ventilation guidelines provided in this document.

9. Avoid Fomites - Remove toys, magazines, and any items that are likely to be shared between patients in the waiting area or consultation chambers. [4]

10. Novel Techniques - Innovative methods have been tried by various doctors and can be utilized.

- Using transparent physical barriers between the patient and doctors can help in decreasing direct exposure to droplets.

- Virtual detailed video interaction followed by a rapid, focused examination of the patient in another chamber minimizes the patient contact time.

- Non-Contact Thermal scanners- These are convenient non-contact devices ideally suited for mass screening in a pandemic and have wide acceptability. However, they lack robust evidence. A recent systematic review

VOLUME 58-APRIL 15, 2021 
showed reasonable diagnostic accuracy in fever detection but may vary with patient characteristics, setting, index test, and the reference standard used. These have an excellent negative predictive value. [9] However, there are more recent studies doubting its accuracy during screening in a pandemic. [10] Hence, no specific recommendations are available for or against the use of these devices.

\section{Personal Protective Equipment [11]}

PPE, along with other measures like engineering and administrative protocols, reduces the exposure of $\mathrm{HCW}$ to infectious agents, including the SARV-CoV2 virus. HCW has 11-fold higher chances of getting infected with the SARS-CoV2 virus than the general population. The use of PPE can reduce that risk by $60-80 \%$ when exposed to COVID-19 suspected or proven cases. Various components of PPE and its benefits are given in Supplementary Table I.

\section{Donning and Doffing PPE}

An essential part of PPE is the proper way of putting it on (Donning) and removing (Doffing) as the maximum chances of contamination and infection occur during doffing. The steps and sequence of donning and doffing of N-95 masks and PPE are given in Supplementary Table II. All PPE components, especially face masks are effective only when used in combination with frequent hand hygiene.

\section{Type of exposure and use of PPE for HCW}

Every patient should be taken as a COVID-19 suspect unless proven otherwise. Appropriate PPE should be universally worn when attending to any patient, even in a non-COVID-19 centre.

- In non-aerosol generation areas - head cap, face mask, goggles, and gloves.

- For aerosol generation areas and procedures - In addition, wear body gowns, shoe cover, and face shield.

- While attending a proven COVID-19 patient - Full Hazmat suit PPE.

- Nonmedical staff not in direct contact with patients triple-layer surgical masks and gloves inside the clinic. They must maintain physical distancing and frequently use hand hygiene.

\section{Patient PPE}

- All patients and their attendants should wear a mask.

- Using a triple layer surgical mask or N-95, if possible, significantly reduces the risk of transmission.

\section{Adjuncts to PPE}

- Patients often complain that the doctor is not audible with PPE. One adjunct is to use a wireless or wired mini personal voice amplifier

- The use of the mobile phone is inevitable but often results in the breach of PPE. Hence, using a blue tooth device, preferably with bone conduction that doesn't plug the ear, is advised.

- Rexene covers or disposable paper covers/sheets for the patient sitting/lying areas.

- Contactless/foot operated dispensers for soap/ sanitizer/water in washbasins.

\section{Sanitization Recommendations}

Despite consistent evidence of contamination of various surfaces with SARS CoV 2 virus, especially in the hospital setting, there is no direct evidence of fomites being a cause of transmission. [12] However, it is imperative to follow some necessary sanitization precautions for the decontamination/disinfection of COVID-19, as given in Table I. These are based on the Hospital Infection Prevention and Control guidelines drafted by the National Centre for Disease Control and the WHO. [13]

\section{Spraying and Fogging}

Spraying, fogging, misting, or fumigation of rooms or surfaces is not recommended for COVID-19. Spraying of chemicals is harmful, affecting the mucus membrane, skin, and respiratory system. The recommended method is to wipe with a disinfectant soaked cloth

\section{Hand Hygiene}

Patients, attendants, and HCW's are advised to wash hands with soap and water in a washbasin with footoperated or motion sensor adapted taps. Everyone should use Foot-operated hand sanitizer dispensers before entering the clinic.

\section{Sanitizers}

The composition of sanitizers is $60-70 \%$ ethanol or isopropyl alcohol. Avoid methanol containing or nonalcohol based sanitizers. Foot operated and Contactless sanitizer delivery systems are safe and effective.

\section{Heating ventilation and air conditioning (HVAC)}

Maintaining the HVAC plays a vital role in providing a stress-free, comfortable, and safe environment for patients and health care workers. Maintaining indoor air quality is very important to prevent cross-contamination and hospital-acquired infections. 
Table I Decontamination and Disinfection Guide

\begin{tabular}{|c|c|c|c|}
\hline Area & Item/Equipment & Process & Procedure \\
\hline General area & Dust Mop & Sweeping & $\begin{array}{l}\text { - } \text { Dust/Wet mop to remove surface dust } \\
\text { - No broom } \\
\text { - Remove gathered dust with hearth brush \& shovel }\end{array}$ \\
\hline $\begin{array}{l}\text { Clinical areas and } \\
\text { waiting rooms }\end{array}$ & $\begin{array}{l}\text { Three buckets each } \\
\text { with Hot Water } \\
\text { Detergent } \\
1 \% \mathrm{NaClO}^{a}\end{array}$ & $\begin{array}{l}\text { Cleaning \& } \\
\text { Mopping }\end{array}$ & $\begin{array}{l}\text { - Prepare a detergent solution with warm water } \\
\text { - Mop with detergent water, allow dry, clean mop with plain } \\
\text { water, squeeze dry, then mop with NaCLO; Mop twice a day } \\
\text { - In areas where there is a spill-using a spill kit, first, discard } \\
\text { the sharps in the sharps bin, then cover any spills with } 1 \% \\
\text { NaCLO for } 10-20 \text { min contact, then wipe and follow the } \\
\text { above standard cleaning process }\end{array}$ \\
\hline \multirow[t]{2}{*}{ Ceiling and walls } & $\begin{array}{l}\text { - Dusting tool with } \\
\text { a long handle } \\
\text { - soap solution } \\
\text { - Plain water }\end{array}$ & Damp dusting & $\begin{array}{l}\text { Damp dusting with very little moisture, just enough to collect } \\
\text { the dust.Done in straight lines that overlap one another. Once } \\
\text { weekly }\end{array}$ \\
\hline & \multicolumn{3}{|c|}{$\begin{array}{l}\text { Care of Mop - Clean with hot water and detergent solution, disinfect it with sodium hypochlorite and keep for } \\
\text { drying upside down }\end{array}$} \\
\hline Doors and doorknobs & $\begin{array}{l}\text { Damp sponge } \\
\text { Detergent } \\
\text { Water }\end{array}$ & $\begin{array}{l}\text { Thorough } \\
\text { Washing }\end{array}$ & - Frequently touched surfaces - cleaned daily \\
\hline \multirow[t]{2}{*}{ Stethoscope } & \multirow[t]{2}{*}{$\begin{array}{l}\mathrm{ABR}^{b} / \text { Spirit } \\
\text { swab }\end{array}$} & \multirow[t]{2}{*}{ Cleaning } & $\begin{array}{l}\text { - Disinfection before every patient contact } \\
\text { - Cleaning with detergent \& water or } 70 \% \text { Isopropyl Alcohol } \\
\text { or } 2 \% \text { bleach solution (may cause discoloration) }\end{array}$ \\
\hline & & & $\begin{array}{l}\text { Do not use Hand sanitizers-(due to harmful additives), } \\
\text { Do not use any sterilization process, never immerse it in any } \\
\text { liquids }\end{array}$ \\
\hline $\begin{array}{l}\text { BP cuffs and } \\
\text { covers }\end{array}$ & $\begin{array}{l}\text { Detergent } \\
\text { Hot water }\end{array}$ & Washing & $\begin{array}{l}\text { - Disinfect covering by wiping with ABR, Regular washing } \\
\text { of the cover }\end{array}$ \\
\hline Thermometer & $\mathrm{ABR}$ & Cleaning & $\begin{array}{l}\text { - Prefer one thermometer per patient } \\
\text { - Disinfect with ABR between every patient }\end{array}$ \\
\hline $\begin{array}{l}\text { Injection and } \\
\text { dressing trolley }\end{array}$ & $\begin{array}{l}\text { Detergent and } \\
\text { water } \\
\text { Duster Disinfectant } \\
(70 \% \text { Alcohol) }\end{array}$ & Cleaning & $\begin{array}{l}\text { To be cleaned daily with detergent and water. } \\
\text { After each use should be wiped with disinfectant. }\end{array}$ \\
\hline Refrigerators & $\begin{array}{l}\text { Detergent and water } \\
\text { Absorbent cloth }\end{array}$ & $\begin{array}{l}\text { Cleaning } \\
\text { (weekly) }\end{array}$ & Defrost, decontaminate, and clean with detergent. \\
\hline Furniture and fittings & $\begin{array}{l}\text { Warm water and } \\
\text { detergent, cloth }\end{array}$ & Dusting & $\begin{array}{l}\text { Using warm water and detergent, damp dust all furniture } \\
\text { \& fittings; }\end{array}$ \\
\hline Curtains & $\begin{array}{l}\text { Soft clothes } \\
\text { Water, Mild soap } \\
\text { solution }\end{array}$ & Cleaning & Clean with water and soap for curtains \\
\hline $\begin{array}{l}\text { Soap dispensers } \\
\text { and water jars }\end{array}$ & $\begin{array}{l}\text { Detergent and } \\
\text { water }\end{array}$ & $\begin{array}{l}\text { Daily } \\
\text { dusting }\end{array}$ & $\begin{array}{l}\text { Soap dispensers- Should be cleaned weekly with detergent } \\
\text { and water and dried. Water jars after cleaning as above, } \\
\text { water to be boiled and cleaned before refilling }\end{array}$ \\
\hline Cleaning of toilets & $\begin{array}{l}\text { Sodium } \\
\text { hypochlorite } 1 \% \\
\text { Soap powder } \\
\text { Long handle } \\
\text { angular brush } \\
\text { Nylon scrubber }\end{array}$ & Cleaning & $\begin{array}{l}\text { Scrub with soap solution, wash with water, then sterilize with } \\
\text { NaCLO } 1 \% \text { for floors and commode. For taps, sink, and } \\
\text { commode accessories, use only soap and water. }\end{array}$ \\
\hline Блупу & a separate drying mo & & \\
\hline
\end{tabular}




\section{Importance of HVAC in the context of COVID 19}

1) The SARS (Severe Acute Respiratory Distress Syndrome) epidemic in the past has taught us that there was an increased rate of intrahospital spread of infection, and it was attributed to architectural factors and HVAC systems. The SARS-CoV2 virus is resistant to various temperatures. Unfortunately, people are switching off air conditioning [AC] facilities to curb the spread. However, this is ineffective and, in fact, harmful as it creates adverse working conditions.

2) It is a misconception that if we maintain moderate humidity, the virus growth and propagation can be prevented. Unfortunately, this virus seems to be very resistant to environmental changes like temperature and humidity. It requires an extreme relative humidity of more than 80 percent and a temperature of more than 50 degrees Centigrade to control. These conditions are neither attainable nor acceptable. [14]

\section{Air changes per hour (ACR)}

Air changes per hour (ACR) are the number of total replacements of any room's air in one hour. If the air supply by the HVAC system in one hour is equal to the volume of the space, then it is called one air change per hour. The number of air exchanges required to clean the air depends on the quantum of infected aerosol production. For example, a minimum of $12 A C R$ is needed in the Intensive Care Unit (ICU). In contrast, only $4 A C R$ is required for general wards, as the expected amount of aerosol production is different in both areas.

There are two ways to reduce the quantum of infection in contaminated air, either by 'diluting' the pathogen (dilution ventilation) or by removing the pathogen (exhaust ventilation). Dilution Ventilation is also called positive pressure isolation, required to prevent infection in an immunocompromised patient. Exhaust Ventilation is called negative pressure isolation and is used primarily to avoid a contaminated patient's

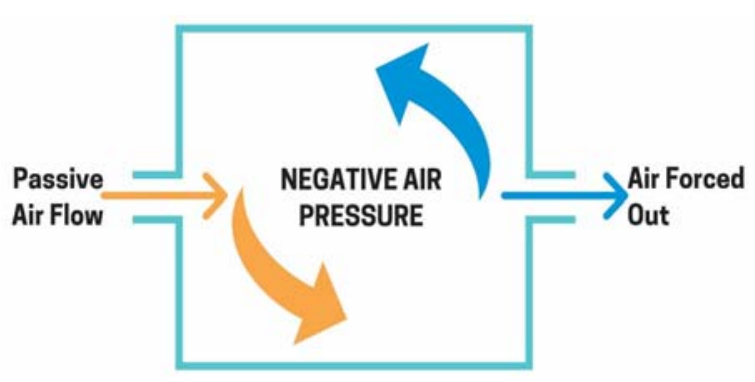

Fig. 1 Principle of HVAC to prevent airborne spread. airborne disease [15] (Fig. 1).

Ways To Create Air Exchanges Via Exhaust Ventilation:

1) Cross Ventilation by opening up doors and windows: This is the cheapest way, but by this method, we cannot control the thermal and pollution level.

2) Exhaust Fan: The exhaust fan creates a negative pressure in the room, which sucks the dirty and contaminated air out of the room, and fresh air is pulled to replace it.

3) Fully Controlled Air: Air inlet, as well as exhaust air, is fully controlled, including the temperature and filtration. This requires a lot of resources, including technology, and is best suited for negative pressure isolation wards and ICUs.

4) Air Purifying Systems: This cleans the air either via filtration (e.g., HEPA) or via other techniques like ultraviolet rays. Recirculation of air has to be prevented for this system to be effective.

The airflow should be in the direction of clean to dirty and should not be directed towards the patient as it causes turbulence. (Fig. 2)

\section{Plasma Purifiers}

Plasma purifiers are specialized newer technology air purifiers. Originally these purifiers were very large and cumbersome, however, with significant advancements in technology, they have become compact and a part of the

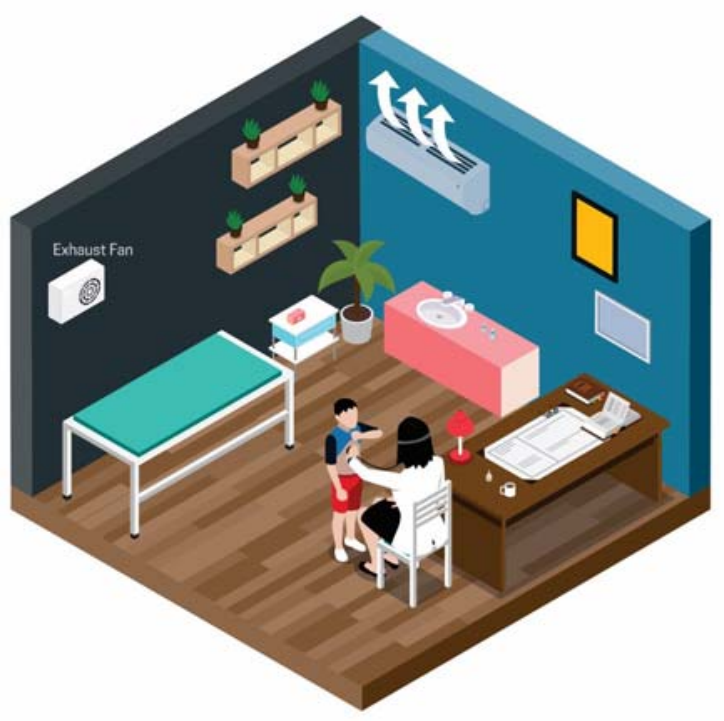

Fig. 2 Clinic setting - Placement of exhaust fan, one feet above the ground. Direction of air should be from clean to dirty (patient side). Flow of AC air should be directed towards celling. 
HVAC with the ionization tubes mounted in the air conditioning, either in the unit itself or in the ductwork. These ionization tubes form ions (negatively or positively charged particles) as air circulates over them. The ions that are produced act in three ways to purify the air:

1) Sterilize bacteria and mould. When bacteria, virus and spores of mould come in contact with the ions, they are oxidized and destroyed. They can no longer multiply and are eliminated from the air.

2) Reduce particles in the air. The ions produced by the system bond with the toxins in the air, causing these particles to become larger. That makes them easier to be capture in the filters, reducing the number of toxin particles in the air.

3) Control odors. Odors associated with household aerosols or cleaning products are "captured" by the ions, oxidized, and eliminated.

The viricidal properties of the Plasma purifiers may be used while installing the HAVAC in the clinics and small establishments. However further evidence is required regarding its efficacy during this pandemic.

Recommended HVAC Modifications For Healthcare Facilities:

Different recommendations for HVAC for various healthcare facilities are given in Supplementary Table III and Figs. 1,2 \& 3.

\section{Covid-19 Exposure In A Non-Covid Health Facility}

There are various situations where a Non-COVID-19 facility is faced with a COVID- 19 challenge. The possible problems and recommendations are enumerated.

When patients admitted for unrelated/non-respiratory illness turn out to be COVID-19 positive

1. Inform the local health authorities

2. Assign anyone dedicated $\mathrm{HCW}$, wearing a full PPE, to attend to this case

3. The patient should be shifted to a separate designated isolation area.

4. Arrange for transfer to a COVID-19 isolation facility after due communication

5. Follow appropriate standard precautions while transporting the patient

6. Followed by disinfection procedures at the facility and the ambulance

7. All contacts (see below) should be identified, risk assessment is done and subsequently follow the testing and quarantine recommendations.

8. All high-risk contacts should be put on Hydroxychloroquine [HCQ] chemoprophylaxis for seven weeks, keeping in mind the contraindications of HCQ.

\section{HCW turn out to be positive for COVID-19 [16]}

1. HCWs developing respiratory symptoms (e.g., fever, cough, shortness of breath) should be considered a suspected case of COVID-19.

2. Should immediately inform his supervisor.

3. Should be isolated, and arrangements must be made to refer to a COVID-19 designated hospital (if not already working in such a facility) for isolation and further management. However, asymptomatic, and mildly symptomatic HCW's need to be home isolated under supervision.

4. Should be immediately taken off the roster

5. All health facilities must have a staffing plan in place for such an event to maintain continuity of operations

6. Ensure that the disinfection procedures are strictly followed

The decision on further /continued use of nonCOVID-19 facilities where a single/multiple

\section{COVID-19 case has been reported [16]}

1. If the hospital authorities are reasonably satisfied that the source case/s have been identified and isolated, all contacts have been traced and quarantined, and adequate disinfection has been achieved, the hospital will continue to function.

2. In addition to the steps taken above, if the health facility continues to report new hospital-acquired COVID-19 cases in the following days, it would be advisable to temporarily close the health facility's defined section where the maximum number of patients are being reported.

3. After thorough cleaning and disinfection, it can be put to use again.

4. Local guidelines for the region should be followed

Standard Operating Procedure to be followed in case HCW reports exposure/breach of PPE [17]

1. All the HCW must report every exposure to COVID-19 to the concerned nodal officer and Head of the concerned department immediately 


\section{Definition of Contacts}

A contact is a person who is likely to get the infection from a positive case through any of the following modes of transmission

- Anyone exposed to a COVID -19 positive case 2 days before and 14 days after the onset of symptoms or date of testing

- The duration ( $>15$ minutes) and proximity $(<1$ meter) of exposure and the use of appropriate PPE during exposure are an important consideration in defining the contact

\section{Primary /High-Risk Contact}

- Anyone with proximity within a 1-meter distance of the confirmed case

- Anyone who touched or cleaned the linens, clothes, utensils of the patient

- Had direct physical contact with the patient including examination or touched the body secretions including blood saliva, urine, etc. without appropriate PPE

- Anyone who has come in contact with aerosolgenerating procedures is considered to be high-risk contact

\section{Secondary/Low-Risk contact}

- Any contact not fitting into the above description

- Low-Risk contacts also can be spreaders of infection hence need monitoring

\section{Risk Assessment}

The risk assessment of close contacts with COVID19 patients is given in Table II.

\section{Recommendations for Monitoring Based on} COVID-19 Exposure Risk [17]

\section{High-and Medium-risk Exposure Category}

- HCW in the high- or medium-risk category should undergo active monitoring, including restriction from work in any healthcare setting until seven days after their last exposure. [18]

- High-risk contacts will be quarantined for seven days

- Test for COVID-19 done on day 0 of exposure and if negative day 7 of exposure

- If they test positive but are asymptomatic, they will follow the protocol for mild/pre-symptomatic cases

- If they test negative and are asymptomatic, they should complete a 7-day quarantine from the last date of exposure and then return to work. Further, they should be in self-reporting observation at work for another minimum of 7 days and strictly abide by the mask and physical distancing rules.

- If they develop a fever (measured temperature $>100 \mathrm{~F}$ or subjective fever) OR respiratory symptoms consistent with COVID-19 (e.g., cough, shortness of breath, sore throat), they should immediately test and self-isolate and notify the senior staff to take further action.

\section{Low-risk Exposure Category}

- HCW in the low-risk category should perform selfmonitoring with delegated supervision until 14 days after the last potential exposure.

- Asymptomatic $\mathrm{HCW}$ in this category are not restricted from work.

- They should check their temperature twice daily and remain alert for respiratory symptoms consistent with COVID-19 (e.g., cough, shortness of breath, sore throat)

- Test for COVID-19 between day 5 and 14 of exposure

- Suppose they develop a fever (measured temperature $>$ $100 \mathrm{~F}$ or subjective fever) OR respiratory symptoms. In that case, they should immediately self-isolate (separate themselves from others) and notify the staff

Table II Risk Assessment of Close Contacts

Prolonged close contact with a COVID-19 patient who was not wearing a facemask (i.e., no source control)

Epidemiological Risk Factor Risk

HCP PPE: None High

HCP PPE: Not wearing a surgical facemask or High N95 mask

HCP PPE: Not wearing eye protection Medium

HCP PPE: Not wearing a gown or gloves Low

HCP PPE: Wearing all recommended PPE (except Low wearing a surgical facemask instead of an N95 mask)

Prolonged close contact with a COVID-19patient who was wearing a facemask (i.e., source control

Epidemiological Risk Factor Risk

HCP PPE: None Medium

HCP PPE: Not wearing a surgical facemask Medium or N95 mask

HCP PPE: Not wearing eye protection Low

HCP PPE: Not wearing a gown or gloves Low

HCP PPE: Wearing all recommended PPE Low

HCP-Healthcare professional; PPE-Personal protective equipment. 
physician promptly so that they can coordinate consultation and referral to a healthcare provider for further evaluation.

Disclaimer: This practice guideline is intended to assist pediatricians and their support staff in safely practicing during the COVID-19 pandemic. The guideline at best serves as a quick reference providing practical advice on continuing medical practice in a safe way in clinics and small establishments. This is a broad advisory and is not intended to override any local or national government policies. This guideline is based on the currently available evidence on COVID-19 and its applicability in the Indian context. With any further developments, the guideline will be subjected to change.

Contributors: SC, DG, AB, GVB: conception and design of the work and drafting the work; BJP, SSK, SD, PN, NS, AB, AJC: substantial contributions to the acquisition and interpretation of data for the work, and revising it critically for important intellectual content. All authors provided approval for the final version to be published.

Funding: None; Competing Interests: None stated.

\section{REFERENCES}

1. Clinical Establishment Act Standards for Clinic / Polyclinic with Dispensary CEA /Clinic- 009 Accessed November 8, 2020. Available from http://clinicalestablishments.gov.in/WriteRead Data/5541.pdf

2. Clinical Establishment Act Standards for Hospital (LEVEL 1A \&1B))/ CEA/Hospital - 001. Accessed November 8, 2020. Available from: http://clinicalestablishments.gov.in/WriteRead Data/147.pdf

3. American Academy of Family Physicians. Checklist to Prepare Physician Offices for COVID-19. Accessed July 28, 2020. Available from https://www.aafp.org/dam/AAFP/documents/ patient_care/publichealth/COVID-19\%20Office\%20Prep $\% 20$ Checklist. pdf

4. Centers for Disease Control. Healthcare Facilities: Get Your Clinic for Corona Virus 2019 (Covid-19). Published March 11, 2020. Accessed July 28, 2020. Available from https://www. cdc.gov/coronavirus/2019-ncov/hcp/clinic-preparedness.html

5. Indian Academy of Pediatrics. Covid-19 Bulletin $2^{\text {nd }}$ Edition. Accessed July 28, 2020. Available from https://iapindia.org/pdf/ Final-Edited-Version-of-IAP-COVID19-Bulletin.pdf

6. Ministry of Health and Family Welfare. Telemedicine Practice Guidelines. Published March 25, 2020. Accessed August 1, 2020. Available from https://www.mohfw.gov.in/pdf/Telemedicine. $p d f$

7. Indian Academy of Pediatrics. COVID-19 Bulletin $2^{\text {nd }}$ Edition. Accessed July 28, 2020. Available from https://iapindia.org/pdf/ Final-Edited-Version-of-IAP-COVID19-Bulletin.pdf

8. Aggarwal N, Garg M, Dwarakanathan V, et al. Diagnostic accuracy of non-contact infrared thermometers and thermal scanners: A systematic review and meta-analysis. J Travel Med. 2020;27:taaa 193 .
9. Khan S, Saultr, B, Adams S, et al. Comparative accuracy testing of non-contact infrared thermometers and temporal artery thermometers in an adult hospital setting. Am J Infect Control. 2020; S0196-6553(20)30892-0. [Epub ahead of print]

10. Guidelines on rational use of personal protective equipment. Ministry of Health and Family Welfare Directorate General of Health Services [Emergency Medical Relief]. Accessed October 25, 2020. Available fromhttps://www.mohfw.gov.in/pdf/Guide linesonrationaluseofPersonalProtectiveEquipment.pdf

11. National Guidelines for Infection Prevention and Control in Healthcare Facilities, Ministry of Health and Family Welfare Directorate General of Health Services, Government of India. Accessed October 25, 2020. https://ncdc.gov.in/index1.php? lang $=1 \&$ level $=1 \&$ sublinkid $=692 \&$ lid $=546$.

12. World health Organization, Transmission of SARS-CoV-2: implications for infection prevention precautions. Scientific Brief. Accessed October 24, 2020. Available from https:// www.who.int/news-room/commentaries/detail/transmission-ofsars-cov-2-implications-for-infection-prevention-precautions

13. How to operate air conditioning and ventilation systems to control the spread of coronavirus disease (COVID-19) in Residences, Workspaces, and Healthcare Facilities: IMA HBIIndian Society of Heating, Refrigerating \& Air Conditioning Engineers COVID-19 GUIDANCE DOCUMENT. Accessed August 11, 2020. Available from https://ishrae.in/mailer/ ISHRAE_COVID-19_Guidelines.pdf

14. World health Organization, Natural Ventilation for Infection Control in Health-Care Settings: Edited by Atkinson J, Chartier Y, Lúcia Pessoa-Silva C, Jensen P, Yuguo Li, Wing-Hong. Accessed August 11, 2020. Available from https://www.who.int/ water_sanitation_health/publications /natural_ventilation

15. Interim United States Guidance for Risk Assessment and Work Restrictions for Healthcare Personnel with Potential Exposure to COVID-19. Accessed October 25, 2020. Available from hhttps://www.cdc.gov/coronavirus/2019-ncov/hcp/guidancerisk-assesment-hcp.html

16. Guidelines to be followed on detection of suspect/confirmed COVID-19 case in a non COVID Health Facility. Ministry of Health \& Family Welfare Directorate General of Health Services Emergency Medical Relief Division. Accessed October 25, 2020. Available from https://www.mohfw.gov.in/pdf/Guide linestobefollowedondetectionofsuspectorconfirmedCOVID 19 case.pdf

17. Revised quarantine and testing protocol for primary/high risk contacts and secondary/low risk contacts. Commissionerate Health \& Family Welfare Services, Government of Karnataka 15-09-20, No DD/SSU/Circular-06/2020-21.

\section{Members of National Expert Committee}

Annexure I

Dr Bakul Jayant Parekh, President IAP 2020, Dr Basavaraja G Chairperson; Prof Arun Bansal - Coordinator; Dr Dhiren Gupta - Convenor; Dr Supraja Chandrasekar, Dr SS Kamath, Dr Snehal Desai, Dr Pritesh Nagar, Dr Nitin Shah, Dr Atanu Bhadra, Dr AJ Chitkara. 